AC 2007-952: GENDER INCLUSIVENESS IN ENGINEERING EDUCATION: IS PROBLEM-BASED LEARNING ENVIRONMENT A RECIPE?

Xiang-Yun Du, Aalborg University

Anette Kolmos, Aalborg University 


\title{
Gender Inclusiveness in Engineering Education - Is Problem Based Learning Environment a Recipe?
}

\begin{abstract}
Based on two $\mathrm{PhD}$ studies on gender recruitment at an engineering univeristy in Denmark, this paper discusses whether and how a PBL environment have been functioning in the recruitment of engineering students. The research findings from both studies show that the PBL environment can be regarded as a learning environment that is friendly to students of both genders. However, it did not witness dramatic increase of women's presence in the past twenty years. Both studies agreed that gender recruitment is not only based on pedagogic model. Therefore, this paper concludes that PBL environment itself is not enough to be used as a recipe for recruiting women to engineering studies. Gender inclusiveness in engineering education is more complex than just establishing a friendly learning environment, and it involves not only increasing the number of women, but also the content aspect towards more contextual learning.
\end{abstract}

\section{Introduction}

The minority of women's participation in engineering programs has been well reported and discussed in feminists' works nearly all around the world. Previous studies have identified various historical reasons leading to this phenomenon. The mostly agreed factors in the history of different western countries include: 1) women's inappropriate gender role, which keeps the ideology of femininity distant from technology and engineering [2, 6, 8, 18, 19, 22], 2) Gender stereotypes in labor division, which defines engineering as a male oriented profession $[1,3,7,11,18]$, and 3) the traditional lecturer-based learning environment at engineering programs overweighs sophisticated natural science knowledge and hard core technological skills, which mainly favors male interest and expectations and ignore women's experiences and concerns $[4,9,24,26,29]$.

To different extents, these historical factors shape young people's educational choices and result in gender disproportionality - men's excessive participation in natural sciences, mathematics, and engineering and women's high participation in arts, humanities, and social sciences [20,27]. Despite their academic qualifications and performance, girls and women markedly do not continue to study mathematics and natural science, and even lower proportions of women study engineering [22].

The past decades witnessed substantial feminist efforts in different western countries aiming at improving women's representation in engineering study programs. One major assumption was that a friendly learning environment can be an option to recruit more women engineering students and promote gender equality in the study of engineering. It is suggested [10] that women's learning is better supported in an environment that is different from those in traditional education and from those that support men's learning. The 'chilly climate' in engineering classrooms has been identified as the major reason that leads to women's inferior experiences to their male peers [9]. Through addressing some commonly identified issues for female students in male dominated courses, Lewis [21] elaborates what is required for technical education to be gender inclusive. She pointed out three aspects that have been neglected in the construction of science and engineering curriculum. They are respectively 1) the construction of the curriculum with the consideration of the students' background 
in light of formal and informal experiences and interests; 2) student/student interactions; 3)

teacher/student interaction. Lewis [21] attributes these issues as main reasons that made the traditional science and engineering curriculum women exclusive, and asserts that real changes need to be made in all these aspects in order to make the environment women friendly.

Gendered proportion is also suggested to be an essential element for the measurement of friendliness of a learning environment, in that it is an important factor influencing the establishment of learning culture [4]. According to Hayes [10], the proportion of female students and teachers in an educational program remains one of the most vital factors deciding the culture. In her study of gender in organizational culture, Kanter [12] suggests that when minority (women in this case) take up less than $15 \%$ of an organization, they can be regarded as token, who are often treated as symbols and representative of the minority category rather than individuals, and a rather balanced situation require at least 30\% [30] or $40 \%-60 \%$ [12] of each group. The experiences of being numeric minority will bring feelings of being isolated, visible and gender stereotyped, in particular, when in nontraditional professions.

Women's ways of knowing and learning have been linked with characteristics of 'connecting' (to others and to the society) and 'collaborative' [28]. In this way, the Problem Based Learning environment has been assumed to be supportive for women's learning in that it is associated with social, sociological, cultural and environmental concerns and learners are expected to be collaborative, communicative, and responsible for management of learning $[5,13,14,25]$.

This paper intends to examine whether and how a student-centred learning environment, Problem Based and Project organized Learning (PBL) can be used as an educational strategy for recruiting women to engineering in Denmark. The paper is based on data from two $\mathrm{PhD}$ studies which were conducted at an engineering university in Denmark where PBL environment has been provided. The first study was conducted from 1985 to 1989 , focusing on women engineering students' learning experiences at different engineering programs. The second study was conducted at the same university from 2003-2006, focusing on both women and men engineering students' learning experiences at two different engineering departments.

A comparison of the two $\mathrm{PhD}$ study shows similar findings: $\mathrm{PBL}$ environment is supportive for the learning processes of both men and women engineering students. However, PBL environment itself is not enough to be used as a recipe for recruiting women to engineering. Young peoples' choice of education is influenced by other factors than choice of learning environment. Furthermore, the two studies indicate that the PBL learning environment provides a workplace imitated learning context, where male students tend to dominate the learning culture by men interest and men ways of working. To a great extent, this might bring barriers to women to participate in project and group work. Therefore, gender inclusiveness in engineering is not solved by PBL learning environment.

\section{Two PhD studies}

This paper draws its research resources from two $\mathrm{PhD}$ studies which were conducted at the same engineering university with the PBL environment provided. A brief overview of the two $\mathrm{PhD}$ studies is illustrated in table 1. 
Table 1 Two $\mathrm{PhD}$ studies on gender and engineering education

\begin{tabular}{|c|c|c|}
\hline Two PhD studies & Kolmos 1989 [15] & Du 2006 [4] \\
\hline Topic & $\begin{array}{l}\text { Gender and knowledge in engineering } \\
\text { education - Women's approach towards } \\
\text { engineering }\end{array}$ & $\begin{array}{l}\text { Bringing new values into engineering } \\
\text { education - Gender and learning in a PBL } \\
\text { environment }\end{array}$ \\
\hline Time & $1985-1989$ & $2003-2006$ \\
\hline Research questions & $\begin{array}{l}\text { - Reasons for mens' and women's choice } \\
\text { of engineering } \\
\text { - Whether women do bring in another } \\
\text { approach compared to their male } \\
\text { colleagues. }\end{array}$ & $\begin{array}{l}\text { - What are the learning experiences of } \\
\text { students of both genders when studying } \\
\text { engineering in a PBL environment? } \\
\text { - How are these experiences influenced } \\
\text { by the prevailing gender relations? }\end{array}$ \\
\hline $\begin{array}{l}\text { Theoretical } \\
\text { perspective }\end{array}$ & Feminist approach & Feminist approach on learning \\
\hline Empirical research & $\begin{array}{l}\text { Qualitative and quantitative studies cross } \\
\text { all engineering programs }\end{array}$ & $\begin{array}{l}\text { Qualitative study at two Engineering } \\
\text { Departments: } \\
\text { Electronics and Computer Engineering (EE) } \\
\text { and Architecture and Design Engineering } \\
\text { (A\&D) }\end{array}$ \\
\hline Methods & $\begin{array}{l}\text { - Questionnaire survey sent out to } 162 \\
\text { respondents and with a response rate on } \\
83 \% \\
\text { - } 17 \text { qualitative interviews with } 13 \\
\text { women and } 4 \text { men. }\end{array}$ & $\begin{array}{l}\text { Qualitative interviews: (1-3 times } \\
\text { interview) } \\
\text { (In EE, } 30 \text { students altogether. } 8 \text { out of } 9 \text { of } \\
\text { the current female students, } 11 \text { male } \\
\text { students; In A\&D, } 40 \text { students - } 21 \text { male } \\
\text { students and } 19 \text { female students); } \\
\text { Observation: with } 4 \text { semester-long projects } \\
\text { ( } 2 \text { groups in each department) }\end{array}$ \\
\hline
\end{tabular}

The first study was conducted in 1986 [15] as one of the first gender studies investigating issues related to gender and PBL funded by an ordinary scholarship from the university. The intention with this study was to find out why women did not choice engineering and how to recruit more women into engineering.

From 2003 to 2006, the second $\mathrm{PhD}$ study [4] was conducted on gender issues in engineering education in Denmark. This PhD study was a joint part of an EU funded project 'Get a Life, Engineer!' managed by the Engineering Society in Denmark, which aims at gender mainstream in engineering profession in general. This $\mathrm{PhD}$ study aimed at exploring barriers to and possibilities of building up a friendly learning environment in Denmark in order to recruit engineering students of both genders. Specifically, this study examined the PBL environment at the same engineering university with the above introduced $\mathrm{PhD}$ study.

Both of the $\mathrm{PhD}$ studies took the theoretical departure from feminist approach with special concerns on women's experiences. Concerning the issue of women's under representation in engineering, both studies ask questions towards individual choices 'why women do not choose engineering studies' as well as structural impact 'why engineering studies do not attract women or exclude women?' Both studies relate gender issues to knowledge and learning, but with different focuses: the first one is from the perspective of psychology [15] and the second one is from the perspective of social learning [4]. 
Based on difference methods, the two studies shared similar findings and conclusions in relation to the gendered experiences of studying engineering, in particular, in hard core technology based study programs. The following of the paper will present selected findings from the two PhD studies. These results will be discussed in relation to the issue of whether and how PBL environment is gender friendly in engineering education based on a comparison of the presented results.

\section{Findings and discussions}

In this paper, two aspects of research findings in the two $\mathrm{PhD}$ studies are presented from a gender perspective: the choice of engineering study and the engineering students' learning experiences of the PBL environment with focuses on two perspectives: the role of team work and identity development in the learning processes.

\section{Choice of engineering study}

Figure 1: Gender distribution in engineering education 1974 - 2006 at Aalborg University

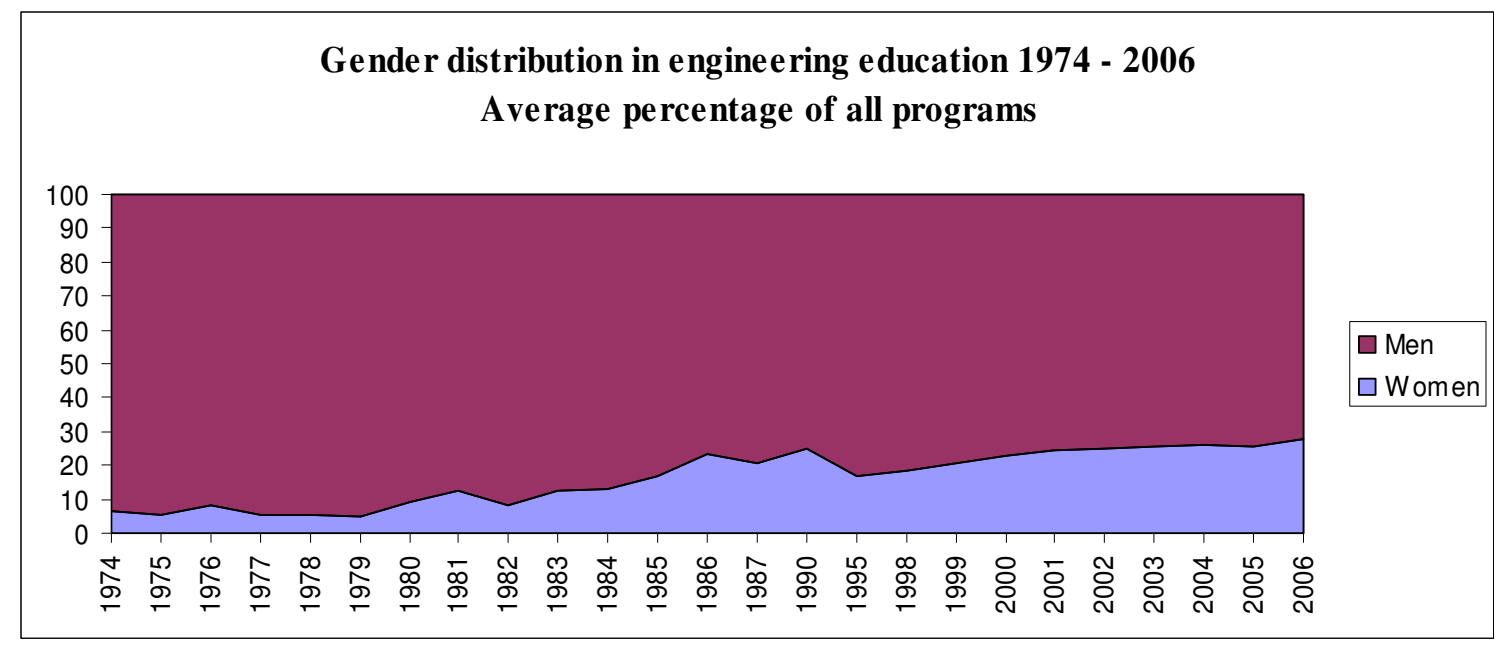

During the 80's women's percentage increased on an average from less than $10 \%$ to more than $20 \%$ at Aalborg University, which was established in 1974 as a problem-based and project-based university. During the 90's, $20 \%$ of women in engineering was stable - however, only due to a growth in new types of engineering programs that attracted women such as Architecture and Design (A\&D), Bio-technology, Health Technology, Global Management. At the traditionally 'hard core' technology based programs like Electrical, Electronics and Computer Engineering, and Mechanical Engineering, civil engineering, women take up no more than $5 \%$ by proportion, for example, among all the present students (around 400) at Department of Electrical, Electronics and Computer Engineering (EE) in autumn, 2003, there were altogether 9 female students. Whereas at the comparatively 'newer' programs like Environmental Management Engineering, Health Science and Technology, Architecture and Design Engineering (A\&D), etc. women take up about $40 \%$ to $60 \%$ by proportion. So there is an important difference in background factors as there at the time the second study was conducted were more engineering programs designed with a more contextual approach that attract women. Students need the same level in mathematics and physics to enrol these new programmes. 
In both $\mathrm{PhD}$ studies, reasons and motives for choosing engineering study were investigated.

In the first study, both the qualitative interviews and the questionnaire documented that the choice of engineering was influenced mainly be the interest for mathematics and physics from high school, future career and inspiration from family. Around $20 \%$ of the female respondents do have a father with engineering background, so that they have experienced what it might be to be an engineer. Half of the interviewed women did have an engineer in the family - father, uncle, cousin, etc.

In the second study, interview data at EE identified a 'natural' process for male students to enter engineering due to their tinkering experiences, interests in technology and the suitable gender role for taking engineering as the future occupation. As one male student said,

'I like computers since when I was very small, I became more and more interested in electronic stuff, so I chose technical highschool, and went to engineering university afterwards so that I could know more about these...'

For the limited female students, their paths to engineering were either influenced by their fathers, boyfriends or other social relationships that were engineers, or motivated by the strong interest in math and good performance in science subjects at upper-secondary schools. As one female student recalled her experiences of making choices,

'I chose math gymnasium because I really like maths but I dared not choose technical highschool there were so many boys there... I got nervous about the idea of going to a school where there were only boys. I was afraid of not fitting into and being good enough for what they are doing. When I finished gymnasium, engineering was the thing I wanted most. I knew that there would be lots of guys in the engineering university, but I still would like to study it, so I chose engineering university.'

At A\&D, few gender-based differences were observed regarding their paths to engineering and learning experiences in the first years. Students of both genders followed similar trajectories to this study program based on their interest in technology, design and creativity. As one female student said,

'I chose it because I was interested in design and technology, and it was a newly established program, actually the only one I could find by then that combined these two aspects. I like technology, but did not want to become a nerd by studying engineering... I would like to do something creative with technology...'

For the choice of universities for engineering study, the majority of the students in both studies made the decision based on their concern of the study form, the PBL environment. However, the recruitment for the university is mainly regional as studies show that around $70 \%$ of all freshmen come from the region [17]. Thus the argument that they choose because of PBL has to be interpreted as a second factor. However, interviews from both studies reveal that for female students the PBL system plays a more important role for their choice as for men. As one female student at EE in the second study said, 
'I knew that I was not good at motivating myself, so I need a group to work in, not for depending on the group members to do the job for me, but for myself to be responsible for work. I need a way to motivate myself... If I have to do all the technical things alone, I would not be able to finish...'

In the interviews in both studies, men do not express similar lack of confidence in motivation for technical content. In that sense the co-operative approach with teamwork may have an additional positive influence on women's experience of the choice of education. However, as the main factor is regional recruitment, compared to other universities, the PBL university do not recruit more women. At other engineering universities, new study programmes were established in the past years, which included different societal aspects in the curricula. These new programs also witnessed increased participation of women (from $30 \%$ to 50\%). Therefore, in terms of numbers and percentage of women, PBL does not lead to an increase. An increase in women seems clearly to be based the content aspect.

\section{Learning experiences in PBL environment}

In general, there are three main characteristics of PBL environment at this university - problem-based and project-based team work. [16, 17]. Studying engineering in the PBL environment, students are expected to develop themselves as problem solvers with the contents knowledge in their discipline as well as develop competencies of management, organization, communication, collaboration and learn

how to learn. Positive effects of PBL environment on studying engineering in general were reported by both studies. Through doing projects in groups, students play an active role in managing their own learning: they learn to take initiatives, set up learning expectations, formulate learning goals, seek various resources for learning, develop learning strategies, have awareness of self-measurement of learning and appreciate the meaningfulness in the learning processes. In addition, both studies documented that the PBL learning environment does not only benefit women but also men. In the following, findings on the role of teamwork and identity development are presented and discussed.

\section{Role of team work}

Team work has been playing an important role in the learning experiences in PBL environment since it is the basic organization of doing project work.

However, in the first study, the questionnaire reveals that women are more positive towards project and team work than men and those women prefer to have more time for project work and more dialogue with project supervisors. Furthermore, women do consider the lectures as an important motivator and the professors' pedagogical skills do play an important role in women's experiences of the learning process. Especially, because for most of the women, they have to create some of their first technical hands on experiences in the engineering education and it is important that professors know how to handle this in a natural way without exposing or disgracing women.

Based on the findings from the second $\mathrm{PhD}$ study, team work has been also mentioned by students of both genders as a beneficial way of learning as a mental support as well as technical strategy. Most interviewed students talked about supports that were received from group members as well as responsibilities that were developed from working in groups. Working in groups was particularly 
referred to as a supportive way to keep women who had strong wish to study engineering from dropping out. As one female student recalled,

'This has been so tough, even though I liked math so much. If it was not because of the group work, I would have dropped out years ago.'

Working in groups provides chances to getting to know the strengths of each other and learning from each other. In general, the research process observed a diversity of individual features in doing project work at both EE and A\&D, especially among male students.

At EE, when talking about their own strengths and contributions, male students normally mentioned different technical areas that they were specifically proud of themselves. Male students in general appreciated the communicational skills that had been developed through group work; however, these skills were not counted as real engineering skills. Technical skills are still regarded as the most important contents for the engineering study. In comparison, female students referred to drawing, calculation and language edition in writing as their main technical contribution. In addition, female students all spoke of their special contribution in terms of planning, coordination, communication and management. As one said,

'I am good at structure. I am the one who is arranging things, making programs and agendas for everyday, structuring what we are doing, and so on. Guys are messy, sometimes they get too involved and tend to forget deadlines.'

However, these features can not replace their lack of technical skills. Female students need to make special efforts to catch up.

At A\&D, gendered features in doing the project work can also be identified, for example, male students are in general regarded (both by themselves and by female students) as better at technology due to their early access to computers. Women are in general better at planning, keeping schedules, being systematic, and managing. Compared with research results from EE, there are two main differences concerning the influence of gendered features on the learning process: 1) at $A \& D$, the gendered features in different aspects of learning processes do not play negative roles in the learning process of to either men or women; 2) at $\mathrm{A} \& \mathrm{D}$, values and contributions of both genders are generally appreciated in the learning culture.

However, in the second study, both interview and observation data at EE show that it was not always a supportive role that team work played on women's experiences. To different degrees, the interviewed female students in EE experienced gender bias in the first year. They sensed that some of their men peer students and professors did not welcome them, or did not take them seriously as would-be engineers. Communication with men peers was difficult for female students in the first years. Most of them had a hard time being accepted from the beginning. They were suspected by the men teaching staff and their men peers with regard to whether they entered the right place. Seven out of the eight women talked about their experiences of 'voice could not be heard' in the first years. They need prove their professional performances in order to be accepted by their male peer and professors. As new comers, they bore heavier burdens than their male peers did. These women had to deal with this pressure and insecurity as they struggled to get through the demanding engineering program. 


\section{Identity development}

Both $\mathrm{PhD}$ studies had a theoretical assumption that learning involves a process of identity work and development, which is shaped in gendered pattern in the experiences of engineering study. The structure of PBL learning environment encompasses established practices for doing engineering work. The learning process involves a shared sense of cultural knowledge that gives meanings to the learners regarding who they are and what they do within the community. This is also a way to develop an engineering identity. The two studies used slightly different methods to approach the identity development; however, both studies found that comparing men and women in engineering, it takes much more energy for women to develop their identity than it does for men. Women's identity work does have a double facet including both gender and professional identity.

In the first study, identity development is analysed according to coping strategies and values. In the first study, the qualitative interviews uncover two types of coping strategies:

- Feminist strategies trying to integrate female values into the technical world and preferring to be together with other women to strengthen possibilities for more gender balanced small talk during breaks.

- A content strategy trying to ignore gender and just being one of the guys.

These findings were echoed in the second study. Female students at EE also talked about their coping strategies in order to survive the study. When they went to later semester of the education, they became more experienced in handling different situations as the minority; they also learned to cooperate well with male peer students and developed good friendships with their male peers. Some of them won the admiration from their male group members, who could appreciate their values and contributions. However, they have been accompanied with the feeling of loneliness along the years of education. All of these female students at EE expressed their wish to have more female students around either for mental support to gain professional confidence, or for a feminine social atmosphere. As one student said that,

\section{'I really wish that there could be seven or eight girls around, it will be much better} than only having the two of us this year.'

However, both studies found that women being together does not always solve their need for a more gendered communication as women do have various interests.

Concerning the relation between gender identity and professional identity, the second study reported different pictures at the two research sites. At EE, it is natural for men to study hard-core engineering and become engineers due to their appropriate gender role. For female students, they become boundarybreakers by entering a male sphere in order to pursue their academic ambition. Being tokens in a malecentred environment, they need to adjust to the engineering ways of working and to become 'one of the guys'. From being different to being accepted, this study witnesses a general adaptation process of these female students. This process cost them special efforts to manage the two conflicting identities, which is something their male peers need not do. However, these women's extra identity work and efforts as the 
cost of studying engineering has not been recognized as a problem by neither these women themselves nor their male peers and teaching staff.

The results from the second study show that it is easier for women at Architecture and Design to cope as women are more than half of the students. The equal proportion by gender makes it easier and comfortable for women to take active participate in different learning activities. In this way, the percentage of women makes a difference.

In addition, the second study shows that the understanding of professional identity is very different at EE and Architecture and Design. At EE there is a long tradition for what kind of careers and jobs they will get after graduation. At Architecture and Design this tradition does not exist as it is a new profession, so the students are very concerned with their future professional identity. Therefore for women engineering student, they might have less work with their gender identity. However, both men and female students are confronted by the challenges of building up a new professional identity.

The other aspect in relation to identity development was men's and women's values in engineering education. In the first study, data from both the questionnaire and the interviews show that women consider more than men the societal aspects and environmental issues and that women get more motivated for the technique by the social purpose and impact and not by the technique it self. Furthermore, this can be seen in their choice of engineering programs at that time as women chose environmental engineering more than mechanics and electronics.

The importance of value in deciding the learning culture was also stated in the second study. The case of EE can be seen as an example of how the historically constructed male norm in engineering still defines the culture of EE engineering in the student-centred learning environment in the current society. The case of A\&D provides an example of different gendered culture. At A\&D, with the increase of women's visibility and active participation, a new engineering culture is being established with the participation of both men and women - being a design engineer is not conflicting with being a woman. As one women said, 'I think that it can be a good thing to have more women in engineering and design work, maybe it sounds stupid, but I think that we will make technology more attractive by bringing our feminine values'.

\section{Conclusions and perspectives}

This paper has made an effort to portray a picture of studying engineering in the PBL environment based on the experiences of students of both genders. In general, the PBL environment provides a supportive milieu in which students of both genders appreciate the meaningfulness of learning, and especially for women to learn technology. Students learned to take responsibilities of their own learning, to take active participation as well as initiate different activities for the purpose of creating learning opportunities to achieve their learning goals. In this way, the PBL environment can be regarded as a learning environment that is friendly to students of both genders. However, it did not witness dramatic increase of women's presence (especially in the hard core technology based programs).

From a feminist perspective, Rosser [23] points out that changing teaching methods is not sufficient for making an education gender-inclusive. Salminen-Karlsson [25] asserts that only focusing on changing teaching methods without increasing the awareness of knowledge of gender issues among the staff will 
limit the changes in curriculum reform and slow down the movement towards a gender-equal curriculum. Based on this, the conclusion on the 'gender-friendly' learning environment should be doubted and questioned.

Therefore, both studies agree that gender recruitment is not only based on pedagogic model. Some of the main factors for women choosing the PBL university is regional recruitment and private knowledge of engineering.

There has not been any dramatic change during the last 20 years. The change that has occurred is the establishment of several new engineering programs that relate engineering with contextual factors such as Health Technology, Global Management, Architecture and Design, etc. Women seek these programs, and there are a percentage of women higher than 30-40\%. This means that it is easier to develop gender identity, but at the same time, it is harder to develop a new professional identity. No matter which choices women make within engineering, they are going to use a lot of energy for identity development.

This paper also shows that gender proportion as an important factor influencing the establishment of learning culture, matters in the way of building up a friendly atmosphere in which learners of both genders can feel comfortable. A conclusion can be made is that women at new engineering programs like Architecture \& Design experience the learning environment much more friendly than women at EE due to the number of women and to the content.

Therefore, PBL environment itself is not enough to be used as a recipe for recruiting women to engineering studies, and it is more complex to examine gender inclusiveness in engineering education than just establishing a friendly learning environment. As a conclusion, this paper proposes that gender inclusiveness in engineering education involves not only increasing the number of women, but also the content aspect towards more contextual learning.

\section{References}

1. Berner, B. \& Mellstrom, U. (1997) Looking for Mister Engineer: Understanding Masculinity and Technology at tow Fin de Siecles. In: Gendered Practices: Feminist Studies of Technology and Society. Berner, B. (eds), pp39-68. Almqvist \& Wiksell International, Stockholm.

2. Chiu, L.H. et al (2002), Engineering and Technology Education for Women in the New Century, Engineering Science and Education Journal, August, 2002, pp145-152.

3. Cockburn, C. (1985) The Material of Male Power. In: The Social Shaping of Technology. Donald, M. \& Wajcman, J. (eds), pp 125-146. Open University Press, Milton Keynes.

4. Du, X. Y. (2006), Bringing New Values into Engineering Education - Gender and Learning in a PBL environment. PhD thesis, Aalborg University, Aalborg.

5. Du, X. Y. (2003), Problem-based Learning - Gender friendly? In: The Proceedings of the 11th International Conference on Gender And Science And Technology (GASAT 11), Mauritius

6. Faulkner, W. Dualisms (2000), Hierarchies and Gender in Engineering, Social Studies of Science, 30 (5), October, 2000, pp759-792.

7. Frehill, L.M (1997)., Education and Occupational Sex Segregation: the Decision to Major in Engineering, Sociological Quarterly, 38 (2), Spring 1997, pp225-249. 
8. Gherardi, S. (1995), Gender, Symbolism and Organizational Culture. SAGE Publications, London.

9. Hacker, S. (1989) Pleasure, Power, and Technology: Some Tales of Gender, Engineering and the Cooperative Workplace. Unwin Hyman, Boston.

10. Hayes, E. (2000), Social Contexts. In: Women as Learners - the Significance of Gender in Adult Learning, Hayes, E. \& Daniele, (eds), pp23-52, Jossey-Bass Publishers, San Francisco.

11. Hersh, M. (2000), The Changing Position of Women in Engineering Worldwide, IEEE Transactions of Engineering Management, Vol.47, No.3, August 2000, pp345-359.

12. Kanter, R. M. (1993), ( $2^{\text {nd }}$ edition) Men and Women of the Corporation. Basic Books, Now York.

13. Kolmos, A. (1996), Reflection on Project Work and Problem-based Learning. European Journal of Engineering Education, Vol. 21, No.2.

14. Kolmos, A. (1992), Metacognitive Aspects in A Group-based Project Work at Technical Universities, Contributions GASAT, the Netherlands.

15. Kolmos, A.. (1989), Kфn og viden i ingeniфruddannelsen, Institut for samfundsudvikling og planlagning. Skriftserie nr. 28, AUC. PhD-afhandling, 195 sider.

16. Kolmos, A., Fink, F, and Krogh, L. (2004), (eds) The Aalborg PBL Model-Progress, Diversity and Challenges, Aalborg University Press

17. Kolmos, A. og Rasmussen, P.(1994), De studerendes holdning til kvaliteten ved den teknisk-naturvidenskabelige basisuddannelse. Institut for Samfundsudvikling og Planlægning, Skriftserie nr. 138, Aalborg Universitet

18. Kvande, E. (1999), In the Belly of the Beast - Constructing Femininities in Engineering Organizations. The European Journal of Women's Studies, No. 6, pp305-328.

19. Kvande, E. \& Rasmussen, B. (1994), Men in Male-Dominated Organizaitons and their Encounter with Women Intruders. Scandinavian Journal of Management, Vol 10, No. 2, pp 164-175.

20. Lackland, A.C. and De Lisi, R., (2001), Students' Choices of College Majors That Are Gender Traditional and Nontraditional, Journal of College Student Development, 42 (1), January-February 2001, pp39-48.

21. Lewis, S. (1993), Including Gender In Higher Education Science and Engineering Courses. In: The Proceedings of GASAT 7 International Conference, pp662-669, Canada.

22. McIlwee, S. \& Robinson, G. (1992), Women in Engineering: Gender, Power, and Workplace Culture. State University of New York Press, Albany.

23. Rosser, S. (1996), Forstering the Advancement of Women in the Sciences, Mathematics and Engineering. In: The Equity Equation. C-S Davis et al (eds), Jossey-Bass, San Francisco.

24. Salminen-Karlsson, M. (2002), Gender Inclusive Computer Engineering Education - Two Attempts at Curriculum Change. International Journal of Engineering Education, 2002, 18 (4), 430-437.

25. Salminen-Karlsson, M. (1999) Bringing Women into Computer Engineering: Curriculum Reform Processes at Two Institutes of Technology. Linköping University, Linköping.

26. Seymour, E and Hewitt, N (1997), Talking about Leaving - Why Undergraduates Leave the Sciences. Boulder, Co: Westview Press. 
27. Smyth, E. (2005). Gender Differentiation and Early Labour Market Integration Across Europe, European Societies 7 (3), 2005, pp451-479.

28. Tarule, J.M., (1996), Voices in Dialogue: Collaborative Ways of Knowing. In: Goldberger et al (eds), Knowledge, Difference, and Power. New York, Basic Books.

29. Tonso, L. (1996) The Impact of Cultural Norms on Women. Journal of Engineering Education, Vol. 86, No. 3, pp217225.

30. Yoder, J. D. (1991) Rethinking Tokenism: Looking Beyond Numbers. Gender and Society, 5(2), pp178-192. 